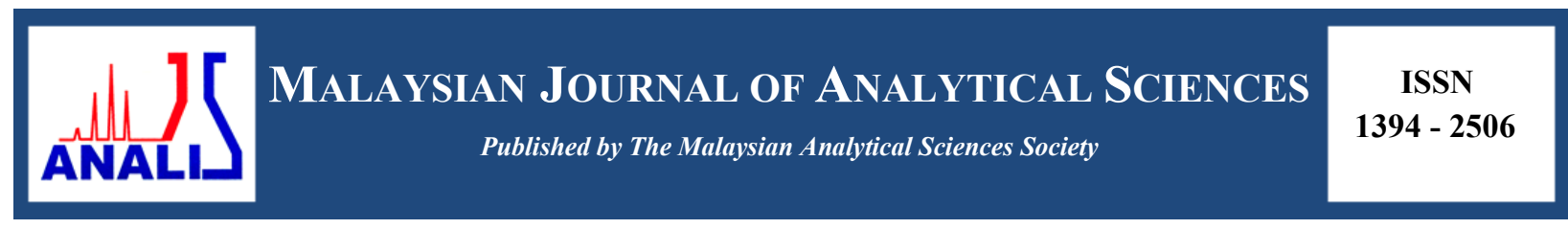

\title{
SYNTHESIS AND ANTIBACTERIAL ACTIVITY OF AZO AND ASPIRIN- AZO DERIVATIVES
}

\author{
(Sintesis dan Aktiviti Antibakteria Terhadap Azo dan Terbitan Azo-Aspirin) \\ Zainab Ngaini and Ho Boon Kui* \\ Department of Chemistry, \\ Faculty of Resource Science and Technology, \\ Universiti Malaysia Sarawak, 94300 Kota Samarahan, Sarawak, Malaysia \\ *Corresponding author: boonkui98@hotmail.com
}

Received: 21 August 2016; Accepted: 27 July 2017

\begin{abstract}
A series of azo derivatives (1a-e) were synthesized via coupling reaction with of overall yield $58-72 \%$ while aspirin-azo derivatives (2a-e) were prepared by esterification reaction of aspirin and azo derivatives (1a-e) with overall yield $38-75 \%$. In this study, the structures of synthesized compounds were characterized using elemental analysis (CHN), nuclear magnetic resonance $\left({ }^{1} \mathrm{H}\right.$ NMR and ${ }^{13} \mathrm{C}$ NMR) and Fourier Transform Infrared (FTIR) spectroscopy. The synthesized compounds were tested on antibacterial activity against Escherichia coli ATCC 25922 and Staphylococcus aureus S48/81 via turbidimetric kinetic method. The azo derivative-substituted fluorine, 1d showed the highest antibacterial activities against Escherichia coli ATCC 25922 and Staphylococcus aureus S48/81 compared with other synthesized compounds. However, synthesized aspirin-azo derivatives (2a-e) showed weak antibacterial activity against tested bacteria due to bulky molecular structure thus hindered the penetration into bacterial cell wall.
\end{abstract}

Keywords: aspirin, azo derivatives, turbidimetric kinetic, Escherichia coli ATCC 25922, Staphylococcus aureus S48/81

Abstrak

Satu siri terbitan azo (1a-e) telah dihasilkan melalui tindak balas gandingan dengan hasil keseluruhan $58-72 \%$ dan terbitan azoaspirin (2a-e) telah disediakan melalui tindak balas esterifikasi aspirin dan terbitan azo (1a-e) dengan hasil keseluruhan 38 $75 \%$. Dalam kajian ini, struktur sebatian yang dihasilkan dicirikan menggunakan analisis unsur (CHN), resonans magnetik nukleus ( ${ }^{1} \mathrm{H}$ NMR dan ${ }^{13} \mathrm{C}$ NMR) dan spektroskopi inframerah transformasi Fourier. Kesemua sebatian yang dihasilkan telah diuji pada aktiviti anti-bakteria terhadap Escherichia coli ATCC 25922 dan Staphylococcus aureus S48 / 81 melalui kaedah kinetik turbidimetrik. Terbitan azo tertukarganti fluorin 1d menunjukkan aktiviti antibakteria tertinggi terhadap Escherichia coli ATCC 25922 dan Staphylococcus aureus S48/81 berbanding dengan sebatian lain. Walau bagaimanapun, terbitan azo aspirin (2a-e) menunjukkan aktiviti anti-bakteria yang lemah terhadap bakteria diuji disebabkan oleh struktur molekul yang besar itu telah menghalang penembusan ke dalam dinding sel bakteria.

Kata kunci: aspirin, terbitan azo, kinetik turbidimetrik, Escherichia coli ATCC 25922, Staphylococcus aureus S48/81

\section{Introduction}

Aspirin is a white crystalline weak acidic product that has analgesic and anti-inflammatory properties $[1,2]$. It is also used to prevent cardiovascular disease and cancer. The compound has an antiplatelet effect by inhibiting the production of thromboxane, which under normal circumstances binds platelet molecules together to create a patch over damaged walls of blood vessels [3]. However, aspirin may cause some side effects such as vomiting and 
stomach bleeding after prolonged usage [4]. Research on aspirin has been studied extensively. Chemical modification of aspirin and its derivatives have improved its pharmacological properties with less gastrointestinal toxicity [5]. Aspirin derivatives were also reported to apply many biological activities such as antibacterial [6], antithrombic [7], antiplatelet and anticancer properties [8].

Azo is a compound which consist of either an aryl or alkyl group functional group (R-N=N-R'). The most stable azo drivatives contain two aryl groups. The presence of $\mathrm{N}=\mathrm{N}$ functional group is claimed to contribute to various applications in food [9], paints [10] and cosmetics [11]. In addition, azo derivatives have been reported to play important roles in many biological processes such as antibacterial [12], antifungal [13], antiviral [14] and anticancer activities [15], which stimulate the interest in the synthesis of a series compound containing aspirin with azo moiety.

In this paper, we report the synthesis of aspirin-azo derivatives 2a-e by reaction of aspirin with azo derivatives 1a-e via esterification. The preparation of halogenated azo derivatives 1a-e was carried out via diazotiation followed by coupling reaction. The antibacterial activity of the synthesized azo derivatives 1a-e and aspirin-azo derivatives 2a-e against Escherichia coli ATCC 25922 and Staphylococcus aureus S48/81 have also been characterized.

\section{Materials and Methods}

Melting point was measured by Stuart SMP3 melting point apparatus and the elemental analysis was determined by flash EA1112 analyzer. IR spectra $\left(v / \mathrm{cm}^{-1}\right)$ were recorded on a Perkin Elmer GX spectrometer with potassium bromide pellet (KBr). ${ }^{1} \mathrm{H}$ and ${ }^{13} \mathrm{C}$ NMR spectra were recorded at $500 \mathrm{MHz}$ on a JEOL.ECA NMR spectrometer.

\section{General method to synthesis of azo derivatives 1a-e}

The general method for synthesizing azo derivatives 1a-e was shown in (Scheme 1). A mixture of $\mathrm{HCl}(2 \mathrm{M}, 6 \mathrm{~mL})$ and aniline derivatives $(0.46 \mathrm{~g}, 5 \mathrm{mmol})$ was added with sodium nitrite solution $(1 \mathrm{M}, 2 \mathrm{~mL})$ in water at $0-5{ }^{\circ} \mathrm{C}$ slowly. Sodium hydroxide $(0.4 \mathrm{~g}, 10 \mathrm{mmol})$ and phenol $(0.47 \mathrm{~g}, 5 \mathrm{mmol})$ dissolved in water $(10 \mathrm{~mL})$ stirred and cooled to $0-5{ }^{\circ} \mathrm{C}$. The diazo salt compound was added slowly into phenol solution at $0-5{ }^{\circ} \mathrm{C}$ and stirred for 40 minutes. The mixture was acidified by adding $2 \mathrm{M} \mathrm{HCl}$. The precipitate formed was filtered and washed with cold water. The crude product was purified by crystallization from hot ethanol to give 1a-e.

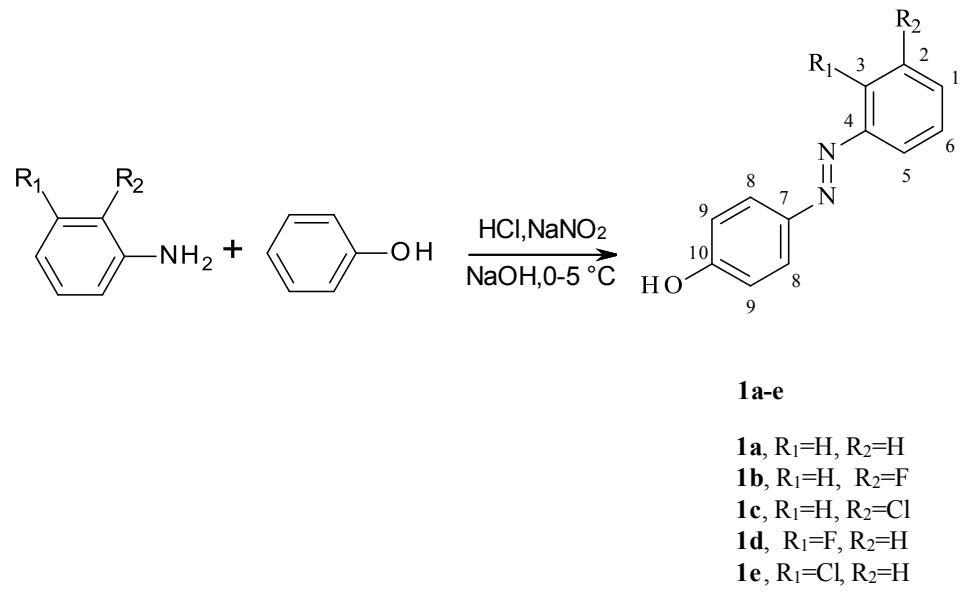

Scheme 1. Synthesis of azo derivatives 1a-e

\section{General method to synthesis of aspirin-azo derivatives 2a-e}

The aspirin-azo derivatives 2a-e can be synthesized from the reaction of aspirin and azo derivatives 1a-e via esterification reaction (Scheme 2). Azo derivatives 1a-e, $(3 \mathrm{mmol})$ was dissolved in dichloromethane $(20 \mathrm{~mL})$ and added into the flask a solution containing acetylsalicylic acid $(0.54 \mathrm{~g}, 3 \mathrm{mmol})$ in dichloromethane $(20 \mathrm{~mL})$ under ice batch. The mixture was added with dicyclohexylcarbodiimide (DCC) $(0.62,3 \mathrm{mmol})$ followed by N,N- 
dimethyl-4-aminopyridine (DMAP) $(0.37 \mathrm{~g}, 3 \mathrm{mmol})$. The reaction mixture was stirred for 4 hours at $0-10{ }^{\circ} \mathrm{C}$ and product formation was accompanied by thin layer chromatography (TLC) analysis using ethyl acetate/hexane (1:4). The white precipitate of by-product (dicyclohexylurea) was filtered off under suction. The filtrate was allowed to be evaporated under vacuum to form precipitate. The precipitate was purified by flash column chromatography on silica gel, using hexane as eluent. The product formed was recrystallized from hot ethanol to give 2a-e.

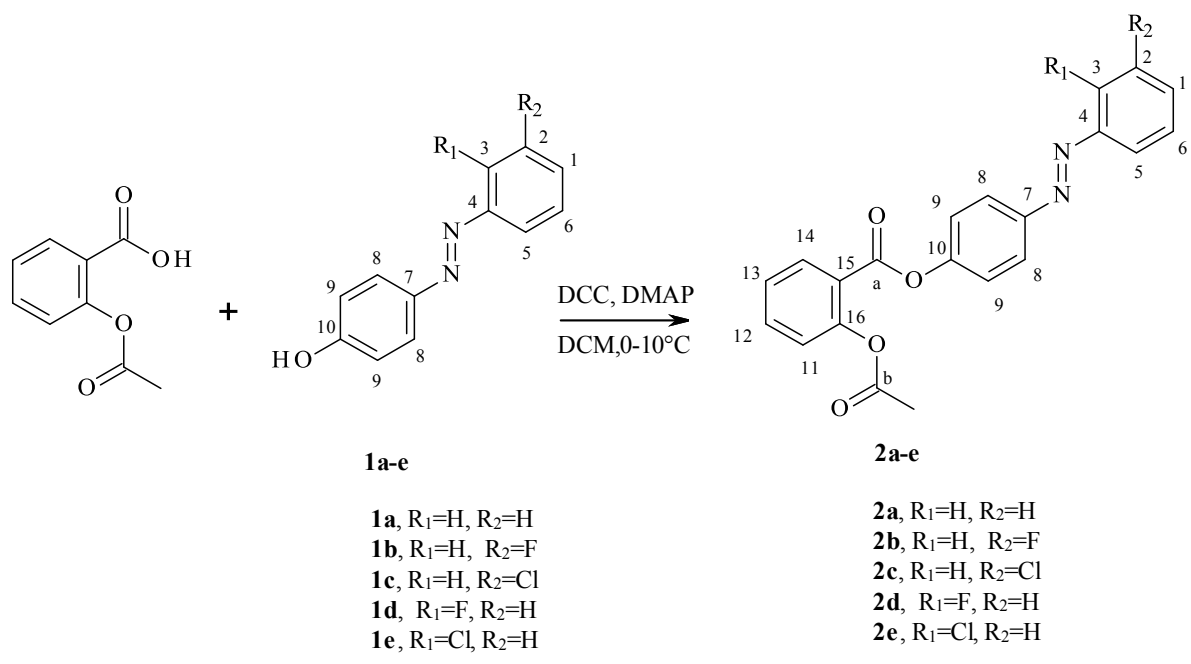

Scheme 2. Synthesis of aspirin-azo derivatives 2a-e

\section{Antibacterial screening}

The antibacterial activities of the synthesized compounds were studied against E. coli and S. aureus. Escherichia coli was cultured on Luria-Bertani (LB) broth and incubated at $37^{\circ} \mathrm{C}$ for 24 hours with shaking at $250 \mathrm{rpm}$ in order to be used as inoculums. Transmittances (T) were recorded in UV-Visible spectrophotometer. Erlenmeyer flasks containing $100 \mathrm{ml}$ of culture medium added with $50 \mathrm{ppm}, 80 \mathrm{ppm}$ and $100 \mathrm{ppm}$ concentrations of compounds and inoculated with $0.99 \mathrm{ml}$ of inoculums and stirred in a culture chamber at $37{ }^{\circ} \mathrm{C}$ with $180 \mathrm{rpm}$. Aliquots were extracted at 1 hour intervals for 6 hours and transmittances $(\mathrm{T})$ were recorded in a UV-Visible spectrophotometer at $560 \mathrm{~nm}$ wavelength. T values were extrapolated to the number of cfu/ml (colony forming units $/ \mathrm{ml}$ ) for E. coli expressed in $\ln \mathrm{N}_{\mathrm{t}}$. The antibacterial screening was repeated by replaced with $S$. aureus [16].

\section{Characterization study}

\section{Results and Discussion}

The structures of 1a-e and 2a-e were confirmed by CHN elemental analysis, FTIR, ${ }^{1} \mathrm{H}$ and ${ }^{13} \mathrm{C}$ NMR spectroscopy. The FTIR spectra of 1a-e and 2a-e showed that the peak observed at $1491-1450 \mathrm{~cm}^{-1}$ was associated to $v(\mathrm{~N}=\mathrm{N})$. The peak observed at $1605-1583 \mathrm{~cm}^{-1}$ was attributed to aromatic $(\mathrm{C}=\mathrm{C})$, while the peak at $764-749 \mathrm{~cm}^{-1}$ and $918-752 \mathrm{~cm}^{-1}$ were corresponded to ortho-substituted of halogen atom and meta-substituted of halogen atom, respectively [17]. In addition, 2a-e showed that disappearance of $v(\mathrm{O}-\mathrm{H})$ peak at $3300-3000 \mathrm{~cm}^{-1}$ and two new strong absorption peaks found at $1772-1732 \mathrm{~cm}^{-1}$ indicated the presence of $v(\mathrm{C}=\mathrm{O})$ stretching of ester bond proved that the reaction was completed.

The ${ }^{1} \mathrm{H}$ and ${ }^{13} \mathrm{C}$ NMR spectroscopy were further confirmed the targeted structures of 1a-e and 2a-e. In the ${ }^{1} \mathrm{H}$ NMR spectra of 1a-e and 2a-e, the aromatic protons were observed at $\delta 8.2-6.9 \mathrm{ppm}$. The ${ }^{1} \mathrm{H}$ NMR spectra of 1a-e showed the presence of $\mathrm{OH}$ group was resonated as singlet at $\delta 10.4-10.3 \mathrm{ppm}\left(\mathrm{DMSO}-\mathrm{d}_{6}\right.$ ) and $\delta 5.8-5.6 \mathrm{ppm}$ $\left(\mathrm{CDCl}_{3}\right)$, while ${ }^{1} \mathrm{H}$ NMR spectra of 2a-e showed the presence of $-\mathrm{CH}_{3}$ appeared as singlet was observed at $\delta 2.28-$ 
Zainab \& Boon: SYNTHESIS AND ANTIBACTERIAL ACTIVITY OF AZO AND ASPIRIN-AZO DERIVATIVES

$2.26 \mathrm{ppm}$. The ${ }^{13} \mathrm{C}$ NMR spectra of 2a-e revealed the $-\mathrm{CH}_{3}$ at $\delta 20.8-20.7 \mathrm{ppm}$. Whereas, the $\mathrm{C}=\mathrm{O}$ was observed at $\delta 169.5-162.0 \mathrm{ppm}$. Other the resonance of aromatic carbon 1a-e and 2a-e were observed at $\delta 163.5-95.6 \mathrm{ppm}$.

[(phenyl)diazenyl]phenol (1a)

(0.67 g, 68\%) yellow solid m.p. $169-171^{\circ} \mathrm{C}$. (Found: C, 72.59; H, 5.02; N, $14.02 \% \mathrm{C}_{12} \mathrm{H}_{10} \mathrm{~N}_{2} \mathrm{O}$ Requires C, 72.73; $\mathrm{H}, 5.05 ; \mathrm{N}, 14.14 \%) ; \mathrm{R}_{\mathrm{f}} 0.55\left(1: 4 \mathrm{EA} /\right.$ hexane) IR: $v_{\max }\left(\right.$ thin film $\left./ \mathrm{cm}^{-1}\right) 3068(\mathrm{OH}), 1583(\mathrm{C}=\mathrm{C}$ aromatic), 1454 $(\mathrm{N}=\mathrm{N}), 1218(\mathrm{C}-\mathrm{N}), 1137(\mathrm{C}-\mathrm{O}), 678,763,835(\mathrm{C}-\mathrm{H}),{ }^{1} \mathrm{H}$ NMR $\left(500 \mathrm{MHz}, \mathrm{DMSO}-\mathrm{d}_{6}\right){ }^{\delta} \mathrm{H}(\mathrm{ppm}): 10.31(\mathrm{~s}, 1 \mathrm{H}$, OH) $7.82-7.80\left(\mathrm{~m}, 4 \mathrm{H}, \mathrm{Ar}-\mathrm{H}_{3,7}\right) 7.57-7.48\left(\mathrm{~m}, 3 \mathrm{H}, \mathrm{Ar}-\mathrm{H}_{1,2,5}\right) 6.94\left(\mathrm{~d}, \mathrm{~J}=8.6 \mathrm{~Hz}, 2 \mathrm{H}, \mathrm{Ar}-\mathrm{H}_{8}\right),{ }^{13} \mathrm{C} \mathrm{NMR}(125 \mathrm{MHz}$, DMSO-d $\left._{6}\right){ }^{\square} \mathrm{C}(\mathrm{ppm}): 160.9\left(\mathrm{Ar}-\mathrm{C}_{9}\right), 152.1\left(\mathrm{Ar}-\mathrm{C}_{4}\right), 145.2\left(\mathrm{Ar}-\mathrm{C}_{6}\right), 130.5\left(\mathrm{Ar}-\mathrm{C}_{1}\right), 129.3\left(\mathrm{Ar}-\mathrm{C}_{2}\right), 124.9\left(\mathrm{Ar}-\mathrm{C}_{7}\right)$, $122.1\left(\mathrm{Ar}-\mathrm{C}_{3}\right), 115.9\left(\mathrm{Ar}-\mathrm{C}_{8}\right)$.

\section{3-[(E)-(Florophenyl)diazenyl]phenol (1b)}

$\left(0.70\right.$ g, $65 \%$ ) yellow solid m.p. $128-129^{\circ} \mathrm{C}$. (Found: C, 66.53; H, 4.30; N, 12.87\% $\mathrm{C}_{12} \mathrm{H}_{9} \mathrm{~N}_{2}$ OF requires C, 66.67; $\mathrm{H}, 4.17 ; \mathrm{N}, 12.96 \%) ; \mathrm{R}_{\mathrm{f}} 0.58\left(1: 4 \mathrm{EA} /\right.$ hexane) IR: $v_{\max }\left(\right.$ thin film $\left./ \mathrm{cm}^{-1}\right) 3157(\mathrm{OH}), 1588(\mathrm{C}=\mathrm{C}$ aromatic $), 1450$ $(\mathrm{N}=\mathrm{N}), 1239(\mathrm{C}-\mathrm{N}), 1145(\mathrm{C}-\mathrm{O}), 840,785,673(\mathrm{C}-\mathrm{F}),{ }^{1} \mathrm{H}$ NMR $\left(500 \mathrm{MHz}, \mathrm{DMSO}-\mathrm{d}_{6}\right)^{\square} \mathrm{H}(\mathrm{ppm}): 10.42(\mathrm{~s}, 1 \mathrm{H}$, OH) $7.81\left(\mathrm{~d}, \mathrm{~J}=8.6 \mathrm{~Hz}, 2 \mathrm{H}, \mathrm{Ar}-\mathrm{H}_{8}\right) 7.61-7.54\left(\mathrm{~m}, 3 \mathrm{H}, \mathrm{Ar}-\mathrm{H}_{1,3,5}\right) 7.33\left(\mathrm{t}, \mathrm{J}=7.2 \mathrm{~Hz}, 1 \mathrm{H}, \mathrm{Ar}_{-} \mathrm{H}_{6}\right) 6.95(\mathrm{~d}, \mathrm{~J}=8.6$ $\left.\mathrm{Hz}, 2 \mathrm{H}, \mathrm{Ar}-\mathrm{H}_{9}\right),{ }^{13} \mathrm{C}$ NMR $\left(125 \mathrm{MHz}, \mathrm{DMSO}-\mathrm{d}_{6}\right){ }^{8} \mathrm{C}(\mathrm{ppm}): 163.5\left(\mathrm{Ar}-\mathrm{C}_{2}\right), 161.6\left(\mathrm{Ar}-\mathrm{C}_{10}\right), 153.5\left(\mathrm{Ar}-\mathrm{C}_{4}\right), 144.8$ $\left(\mathrm{Ar}-\mathrm{C}_{7}\right), 130.9\left(\mathrm{Ar}-\mathrm{C}_{6}\right), 125.0\left(\mathrm{Ar}-\mathrm{C}_{8}\right), 119.6\left(\mathrm{Ar}-\mathrm{C}_{5}\right), 116.8\left(\mathrm{Ar}-\mathrm{C}_{1}\right), 115.9\left(\mathrm{Ar}-\mathrm{C}_{9}\right), 106.9\left(\mathrm{Ar}-\mathrm{C}_{3}\right)$.

\section{3-[(E)-(Chlorophenyl)diazenyl]phenol (1c)}

$\left(0.79\right.$ g, 68\%) red solid m.p. $140-141{ }^{\circ} \mathrm{C}$. (Found: $\mathrm{C}, 61.51 ; \mathrm{H}, 3.86 ; \mathrm{N}, 12.01 \% \mathrm{C}_{12} \mathrm{H}_{9} \mathrm{~N}_{2} \mathrm{OCl}$ requires C, 61.94; $\mathrm{H}$, 3.87; N, 12.04\%); $\mathrm{R}_{\mathrm{f}} 0.54\left(1: 4 \mathrm{EA} /\right.$ hexane) IR: $v_{\max }$ (thin film $\left./ \mathrm{cm}^{-1}\right) 3253(\mathrm{OH}), 1596(\mathrm{C}=\mathrm{C}$ aromatic), 1476 $(\mathrm{N}=\mathrm{N}), 1253(\mathrm{C}-\mathrm{N}), 1151(\mathrm{C}-\mathrm{O}), 833,788,675(\mathrm{C}-\mathrm{Cl}),{ }^{1} \mathrm{H}$ NMR $\left(500 \mathrm{MHz}, \mathrm{DMSO}-\mathrm{d}_{6}\right){ }^{8} \mathrm{H}(\mathrm{ppm}): 10.44(\mathrm{~s}, 1 \mathrm{H}$, OH) $8.08\left(\mathrm{~s}, 1 \mathrm{H}, \mathrm{Ar}-\mathrm{H}_{3}\right) 7.86-7.81\left(\mathrm{~m}, 4 \mathrm{H}, \mathrm{Ar}-\mathrm{H}_{1,5,8}\right) 7.36\left(\mathrm{t}, \mathrm{J}=7.7 \mathrm{~Hz}, 1 \mathrm{H}, \mathrm{Ar}-\mathrm{H}_{6}\right) 6.94(\mathrm{~d}, \mathrm{~J}=9.2 \mathrm{~Hz}, 2 \mathrm{H}, \mathrm{Ar}-$ $\left.\mathrm{H}_{9}\right),{ }^{13} \mathrm{C}$ NMR $\left(125 \mathrm{MHz}\right.$, DMSO-d $\left.{ }_{6}\right){ }^{8} \mathrm{C}(\mathrm{ppm}): 161.8\left(\mathrm{Ar}-\mathrm{C}_{10}\right), 153.4\left(\mathrm{Ar}-\mathrm{C}_{4}\right), 145.3\left(\mathrm{Ar}-\mathrm{C}_{7}\right), 134.3\left(\mathrm{Ar}-\mathrm{C}_{2}\right), 131.4$ $\left(\mathrm{Ar}-\mathrm{C}_{1}\right), 130.2\left(\mathrm{Ar}-\mathrm{C}_{6}\right), 125.5\left(\mathrm{Ar}-\mathrm{C}_{8}\right), 122.3\left(\mathrm{Ar}-\mathrm{C}_{3}\right), 120.7\left(\mathrm{Ar}-\mathrm{C}_{5}\right), 116.3\left(\mathrm{Ar}-\mathrm{C}_{9}\right)$.

\section{2-[(E)-(Florophenyl)diazenyl]phenol (1d)}

$\left(0.67 \mathrm{~g}, 62 \%\right.$ ) orange solid m.p. $104-105^{\circ} \mathrm{C}$. (Found: C, 65.99; H, 4.10; N, 12.88\% $\mathrm{C}_{12} \mathrm{H}_{9} \mathrm{~N}_{2} \mathrm{OF}$ requires C, 66.67; $\mathrm{H}, 4.17 ; \mathrm{N}, 12.96 \%) ; \mathrm{R}_{\mathrm{f}} 0.56\left(1: 4 \mathrm{EA} /\right.$ hexane) IR: $v_{\max }\left(\right.$ thin film $\left./ \mathrm{cm}^{-1}\right) 3303(\mathrm{OH}), 1585(\mathrm{C}=\mathrm{C}$ aromatic $), 1480$ $(\mathrm{N}=\mathrm{N}), 1212(\mathrm{C}-\mathrm{N}), 1142(\mathrm{C}-\mathrm{O}), 753(\mathrm{C}-\mathrm{F}),{ }^{1} \mathrm{H}$ NMR $\left(500 \mathrm{MHz}, \mathrm{DMSO}-\mathrm{d}_{6}\right){ }^{8} \mathrm{H}(\mathrm{ppm}): 10.43(\mathrm{~s}, 1 \mathrm{H}, \mathrm{OH}), 7.81(\mathrm{~d}$, $\left.\mathrm{J}=8.6 \mathrm{~Hz}, 2 \mathrm{H}, \mathrm{Ar}-\mathrm{H}_{5}\right), 7.66\left(\mathrm{t}, \mathrm{J}=7.7 \mathrm{~Hz}, 1 \mathrm{H}, \mathrm{Ar}-\mathrm{H}_{1}\right), 7.53\left(\mathrm{~d}, \mathrm{~J}=8.2 \mathrm{~Hz}, 1 \mathrm{H}, \mathrm{Ar}-\mathrm{H}_{8}\right), 7.45(\mathrm{~d}, \mathrm{~J}=8 \mathrm{~Hz}, 1 \mathrm{H}, \mathrm{Ar}-$ $\left.\mathrm{H}_{2}\right), 7.31\left(\mathrm{t}, \mathrm{J}=7.2 \mathrm{~Hz}, 1 \mathrm{H}, \mathrm{Ar}-\mathrm{H}_{6}\right), 6.95\left(\mathrm{~d}, \mathrm{~J}=8.6 \mathrm{~Hz}, 2 \mathrm{H}, \mathrm{Ar}-\mathrm{H}_{9}\right),{ }^{13} \mathrm{C}$ NMR $\left(125 \mathrm{MHz}, \mathrm{DMSO}-\mathrm{d}_{6}\right){ }^{8} \mathrm{C}(\mathrm{ppm})$ : 115.9 (Ar-C $\left.)_{9}\right), 117.0\left(\mathrm{Ar}-\mathrm{C}_{2}\right), 117.1\left(\mathrm{Ar}-\mathrm{C}_{8}\right), 117.9\left(\mathrm{Ar}-\mathrm{C}_{5}\right), 124.1\left(\mathrm{Ar}-\mathrm{C}_{6}\right), 125.5\left(\mathrm{Ar}-\mathrm{C}_{1}\right), 131.8\left(\mathrm{Ar}-\mathrm{C}_{4}\right), 140.9(\mathrm{Ar}-$ $\left.\mathrm{C}_{7}\right), 147.6\left(\mathrm{Ar}-\mathrm{C}_{3}\right), 159.1\left(\mathrm{Ar}-\mathrm{C}_{10}\right)$.

\section{2-[(E)-(Chlorophenyl)diazenyl]phenol (1e)}

$\left(0.67 \mathrm{~g}, 58 \%\right.$ ) orange solid m.p. $112-113^{\circ} \mathrm{C}$. (Found: C, 61.32; H, 3.76; N, 11.95\% $\mathrm{C}_{12} \mathrm{H}_{9} \mathrm{~N}_{2} \mathrm{OCl}$ requires C, 61.94; $\mathrm{H}, 3.87 ; \mathrm{N}, 12.04 \%) ; \mathrm{R}_{\mathrm{f}} 0.53\left(1: 4 \mathrm{EA} /\right.$ hexane) IR: $v_{\max }\left(\right.$ thin film $\left./ \mathrm{cm}^{-1}\right) 3301(\mathrm{OH}), 1588(\mathrm{C}=\mathrm{C}$ aromatic $), 1483$ $(\mathrm{N}=\mathrm{N}), 1238(\mathrm{C}-\mathrm{N}), 1139(\mathrm{C}-\mathrm{O}), 754(\mathrm{C}-\mathrm{Cl}),{ }^{1} \mathrm{H}$ NMR $\left(500 \mathrm{MHz}, \mathrm{CDCl}_{3}\right){ }^{8} \mathrm{H}(\mathrm{ppm}): 7.92(\mathrm{~d}, \mathrm{~J}=8.6 \mathrm{~Hz}, 2 \mathrm{H}, \mathrm{Ar}-$ $\left.\mathrm{H}_{8}\right), 7.66\left(\mathrm{~d}, \mathrm{~J}=7.4 \mathrm{~Hz}, 1 \mathrm{H}, \mathrm{Ar}-\mathrm{H}_{5}\right), 7.53\left(\mathrm{~d}, \mathrm{~J}=7.4 \mathrm{~Hz}, 1 \mathrm{H}, \mathrm{Ar}-\mathrm{H}_{2}\right), 7.34\left(\mathrm{~m}, 2 \mathrm{H}, \mathrm{Ar}-\mathrm{H}_{1,6}\right), 6.95(\mathrm{~d}, \mathrm{~J}=8.6 \mathrm{~Hz}, 2 \mathrm{H}$, Ar- $\left.\mathrm{H}_{9}\right), 5.72(\mathrm{~s}, 1 \mathrm{H}, \mathrm{OH}),{ }^{13} \mathrm{C}$ NMR $\left(125 \mathrm{MHz}, \mathrm{DMSO}-\mathrm{d}_{6}\right){ }^{8} \mathrm{C}(\mathrm{ppm}): 161.6\left(\mathrm{Ar}-\mathrm{C}_{10}\right), 148.1\left(\mathrm{Ar}-\mathrm{C}_{4}\right), 145.5\left(\mathrm{Ar}-\mathrm{C}_{7}\right)$, 133.1 (Ar- $\left.\mathrm{C}_{1}\right), 131.6\left(\mathrm{Ar}-\mathrm{C}_{2}\right), 130.6\left(\mathrm{Ar}-\mathrm{C}_{6}\right), 127.9\left(\mathrm{Ar}-\mathrm{C}_{3}\right), 125.4\left(\mathrm{Ar}-\mathrm{C}_{5}\right), 117.5\left(\mathrm{Ar}-\mathrm{C}_{8}\right), 116.1\left(\mathrm{Ar}-\mathrm{C}_{9}\right)$.

\section{[(phenyl)diazenyl]phenylaspirinate (2a)}

(0.81 g, 75\%) pale yellow solid m.p. $168-170{ }^{\circ}$ C. (Found: C, 69.97; H, 4.46; N, 7.67\% $\mathrm{C}_{12} \mathrm{H}_{9} \mathrm{~N}_{2} \mathrm{OI}$ requires C, 70.0; $\mathrm{H}, 4.17 ; \mathrm{N}, 7.78 \%) ; \mathrm{R}_{\mathrm{f}} 0.64\left(1: 4 \mathrm{EA} /\right.$ hexane) IR: $v_{\max }\left(\right.$ thin film $\left./ \mathrm{cm}^{-1}\right) 1736,1763(\mathrm{C}=\mathrm{O}), 1604(\mathrm{C}=\mathrm{C}$ aromatic $)$, $1481(\mathrm{~N}=\mathrm{N}), 1249(\mathrm{C}-\mathrm{N}), 1183(\mathrm{C}-\mathrm{O}), 762,686(\mathrm{C}-\mathrm{H}){ }^{1} \mathrm{H}$ NMR $\left(500 \mathrm{MHz}, \mathrm{DMSO}-\mathrm{d}_{6}\right){ }^{8} \mathrm{H}(\mathrm{ppm}): 8.20(\mathrm{~d}, \mathrm{~J}=9.2$ $\left.\mathrm{Hz}, 1 \mathrm{H}, \operatorname{Ar}-\mathrm{H}_{14}\right), 8.01\left(\mathrm{~d}, \mathrm{~J}=9.2 \mathrm{~Hz}, 2 \mathrm{H}, \mathrm{Ar}-\mathrm{H}_{7}\right), 7.91\left(\mathrm{~d}, \mathrm{~J}=8.6 \mathrm{~Hz}, 2 \mathrm{H}, \mathrm{Ar}-\mathrm{H}_{3}\right), 7.79\left(\mathrm{t}, \mathrm{J}=7.7 \mathrm{~Hz}, 1 \mathrm{H}, \mathrm{Ar}-\mathrm{H}_{13}\right)$, $7.64-7.58\left(\mathrm{~m}, 3 \mathrm{H}, \mathrm{Ar}-\mathrm{H}_{1,2,5}\right), 7.51\left(\mathrm{t}, \mathrm{J}=7.8 \mathrm{~Hz}, 1 \mathrm{H}, \mathrm{Ar}-\mathrm{H}_{13}\right), 7.48\left(\mathrm{~d}, \mathrm{~J}=8.6 \mathrm{~Hz}, 2 \mathrm{H}, \mathrm{Ar}-\mathrm{H}_{8}\right), 7.35(\mathrm{~d}, \mathrm{~J}=8 \mathrm{~Hz}$, $\left.1 \mathrm{H}, \mathrm{Ar}-\mathrm{H}_{11}\right), 2.27\left(\mathrm{~s}, 3 \mathrm{H},-\mathrm{CH}_{3}\right),{ }^{13} \mathrm{C}$ NMR $\left(125 \mathrm{MHz}, \mathrm{DMSO}-\mathrm{d}_{6}\right){ }^{8} \mathrm{C}(\mathrm{ppm}): 169.3\left(\mathrm{C}_{\mathrm{b}}=\mathrm{O}\right), 162.4\left(\mathrm{C}_{\mathrm{a}}=\mathrm{O}\right), 152.4$ 
$\left(\mathrm{Ar}-\mathrm{C}_{4}\right), 151.9\left(\mathrm{Ar}-\mathrm{C}_{9}\right), 149.8\left(\mathrm{Ar}-\mathrm{C}_{6}\right), 150.5\left(\mathrm{Ar}-\mathrm{C}_{10}\right), 135.3\left(\mathrm{Ar}-\mathrm{C}_{12}\right), 131.9\left(\mathrm{Ar}-\mathrm{C}_{1}\right), 131.7\left(\mathrm{Ar}-\mathrm{C}_{14}\right), 129.5\left(\mathrm{Ar}-\mathrm{C}_{2}\right)$, 126.6 (Ar- $\left.\mathrm{C}_{13}\right), 124.2\left(\mathrm{Ar}-\mathrm{C}_{11}\right), 124.0\left(\mathrm{Ar}-\mathrm{C}_{7}\right), 122.9\left(\mathrm{Ar}-\mathrm{C}_{3}\right), 122.6\left(\mathrm{Ar}-\mathrm{C}_{8}\right), 121.9\left(\mathrm{Ar}-\mathrm{C}_{15}\right), 20.8\left(-\mathrm{CH}_{3}\right)$.

\section{3-[(E)-(Florophenyl)diazenyl]phenylaspirinate (2b)}

$(0.62 \mathrm{~g}, 55 \%)$ pale yellow solid. m.p. $150-151{ }^{\circ} \mathrm{C}$. (Found: $\mathrm{C}, 66.61 ; \mathrm{H}, 4.04 ; \mathrm{N}, 7.33 \% \mathrm{C}_{21} \mathrm{H}_{15} \mathrm{~N}_{2} \mathrm{O}_{4} \mathrm{~F}$ requires C, 66.67; H, 3.97; N, 7.41\%); $\mathrm{R}_{\mathrm{f}} 0.65\left(1: 4 \mathrm{EA} /\right.$ hexane) IR: $v_{\max }\left(\right.$ thin film $\left./ \mathrm{cm}^{-1}\right) 1768,1742(\mathrm{C}=\mathrm{O}), 1592(\mathrm{C}=\mathrm{C}$ aromatic), $1453(\mathrm{~N}=\mathrm{N}), 1244$ (C-N), $1186(\mathrm{C}-\mathrm{O}), 914,884,785$ (C-F), ${ }^{1} \mathrm{H}$ NMR (500 MHz, DMSO-d 6 ) ${ }^{8} \mathrm{H}(\mathrm{ppm})$ : $8.20\left(\mathrm{~d}, \mathrm{~J}=7.5 \mathrm{~Hz}, 1 \mathrm{H}, \mathrm{Ar}-\mathrm{H}_{15}\right), 8.03\left(\mathrm{~d}, \mathrm{~J}=8.6 \mathrm{~Hz}, 2 \mathrm{H}, \mathrm{Ar}-\mathrm{H}_{8}\right), 7.83-7.79\left(\mathrm{~m}, 2 \mathrm{H}, \mathrm{Ar}-\mathrm{H}_{6,14}\right), 7.71-7.66(\mathrm{~m}, 2 \mathrm{H}$, $\left.\mathrm{Ar}-\mathrm{H}_{3,5}\right), 7.54-7.45\left(\mathrm{~m}, 4 \mathrm{H}, \mathrm{Ar}-\mathrm{H}_{1,9}, 13\right) 7.35\left(\mathrm{~d}, \mathrm{~J}=8.0 \mathrm{~Hz}, 1 \mathrm{H}, \mathrm{Ar}-\mathrm{H}_{12}\right), 2.27\left(\mathrm{~s}, 3 \mathrm{H},-\mathrm{CH}_{3}\right),{ }^{13} \mathrm{C}$ NMR $(125 \mathrm{MHz}$, DMSO- $\left.\mathrm{d}_{6}\right)^{8} \mathrm{C}(\mathrm{ppm}): 169.3\left(\mathrm{C}_{\mathrm{b}}=\mathrm{O}\right), 163.7\left(\mathrm{C}_{\mathrm{a}}=\mathrm{O}\right), 162.4\left(\mathrm{Ar}-\mathrm{C}_{2}\right), 161.6\left(\mathrm{Ar}-\mathrm{C}_{4}\right), 153.4\left(\mathrm{Ar}-\mathrm{C}_{10}\right), 152.8\left(\mathrm{Ar}-\mathrm{C}_{11}\right)$, $150.5\left(\mathrm{Ar}-\mathrm{C}_{7}\right), 149.9\left(\mathrm{Ar}-\mathrm{C}_{13}\right), 135.4\left(\mathrm{Ar}-\mathrm{C}_{15}\right), 131.9\left(\mathrm{Ar}-\mathrm{C}_{6}\right), 131.4\left(\mathrm{Ar}-\mathrm{C}_{14}\right), 126.6\left(\mathrm{Ar}-\mathrm{C}_{12}\right), 124.3\left(\mathrm{Ar}-\mathrm{C}_{8}\right), 123.1$ $\left(\mathrm{Ar}-\mathrm{C}_{9}\right), 121.9\left(\mathrm{Ar}-\mathrm{C}_{16}\right), 120.51\left(\mathrm{Ar}-\mathrm{C}_{5}\right), 117.9\left(\mathrm{Ar}-\mathrm{C}_{1}\right), 107.6\left(\mathrm{Ar}-\mathrm{C}_{3}\right), 20.8\left(-\mathrm{CH}_{3}\right)$.

\section{3-[(E)-(Chlorophenyl)diazenyl]phenylaspirinate (2c)}

(0.57 g, 48\%) pale yellow solid m.p. $153-154^{\circ} \mathrm{C}$. (Found: C, 63.39; H, 3.78; N, 7.04\% $\mathrm{C}_{21} \mathrm{H}_{15} \mathrm{~N}_{2} \mathrm{O}_{4} \mathrm{Cl}$ requires C, 63.88; H, 3.80; N, 7.10\%); $\mathrm{R}_{\mathrm{f}} 0.62\left(1: 4 \mathrm{EA} /\right.$ hexane) IR: $v_{\max }\left(\right.$ thin film $\left./ \mathrm{cm}^{-1}\right) 1760,1733(\mathrm{C}=\mathrm{O}), 1605(\mathrm{C}=\mathrm{C}$ aromatic), $1484(\mathrm{~N}=\mathrm{N}), 1248(\mathrm{C}-\mathrm{N}), 1184(\mathrm{C}-\mathrm{O}), 785,885,918(\mathrm{C}-\mathrm{Cl}),{ }^{1} \mathrm{H}$ NMR $\left(500 \mathrm{MHz}, \mathrm{DMSO}-\mathrm{d}_{6}\right)^{\delta} \mathrm{H}(\mathrm{ppm})$ : $8.20\left(\mathrm{~d}, \mathrm{~J}=7.6 \mathrm{~Hz}, 1 \mathrm{H}, \mathrm{Ar}-\mathrm{H}_{15}\right), 8.03\left(\mathrm{~d}, \mathrm{~J}=8.60 \mathrm{~Hz}, 2 \mathrm{H}, \mathrm{Ar}-\mathrm{H}_{8}\right), 7.92-7.90\left(\mathrm{~m}, 2 \mathrm{H}, \mathrm{Ar}-\mathrm{H}_{3,14}\right), 7.79$ (t, J = $7.7 \mathrm{~Hz}$, $\left.1 \mathrm{H}, \mathrm{Ar}-\mathrm{H}_{6}\right), 7.68-7.66\left(\mathrm{~m}, 2 \mathrm{H}, \mathrm{Ar}-\mathrm{H}_{1,5}\right), 7.55-7.50\left(\mathrm{~m}, 3 \mathrm{H}, \mathrm{Ar}-\mathrm{H}_{9,13}\right), 7.35$ (d, J = 8.0 Hz, 1H, Ar- $\left.\mathrm{H}_{12}\right), 2.27(\mathrm{~s}$, $\left.3 \mathrm{H},-\mathrm{CH}_{3}\right),{ }^{13} \mathrm{C}$ NMR $\left(125 \mathrm{MHz}, \mathrm{DMSO}-\mathrm{d}_{6}\right){ }^{8} \mathrm{C}(\mathrm{ppm}): 169.2\left(\mathrm{C}_{\mathrm{b}}=\mathrm{O}\right), 162.4\left(\mathrm{C}_{\mathrm{a}}=\mathrm{O}\right), 152.8\left(\mathrm{Ar}-\mathrm{C}_{4}\right), 150.5\left(\mathrm{Ar}-\mathrm{C}_{10}\right)$, 149.7 $\left(\mathrm{Ar}^{-\mathrm{C}_{11}}\right), 135.4\left(\mathrm{Ar}-\mathrm{C}_{7}\right), 134.2\left(\mathrm{Ar}-\mathrm{C}_{13}\right), 131.9\left(\mathrm{Ar}-\mathrm{C}_{2}\right), 131.3\left(\mathrm{Ar}-\mathrm{C}_{1}\right), 131.2\left(\mathrm{Ar}-\mathrm{C}_{15}\right), 126.6\left(\mathrm{Ar}-\mathrm{C}_{6}\right), 124.3$ $\left(\mathrm{Ar}-\mathrm{C}_{14}\right), 124.1\left(\mathrm{Ar}-\mathrm{C}_{12}\right), 123.1\left(\mathrm{Ar}-\mathrm{C}_{8}\right), 122.6\left(\mathrm{Ar}-\mathrm{C}_{3}\right), 121.9\left(\mathrm{Ar}-\mathrm{C}_{9}\right), 121.6\left(\mathrm{Ar}-\mathrm{C}_{5}\right), 121.0\left(\mathrm{Ar}-\mathrm{C}_{16}\right), 20.7\left(-\mathrm{CH}_{3}\right)$.

\section{2-[(E)-(Florophenyl)diazenyl]phenylaspirinate (2d)}

$\left(0.45 \mathrm{~g}, 40 \%\right.$ ) pale yellow $123-124^{\circ} \mathrm{C}$. (Found: $\mathrm{C}, 66.52 ; \mathrm{H}, 3.91 ; \mathrm{N}, 7.22 \% \mathrm{C}_{21} \mathrm{H}_{15} \mathrm{~N}_{2} \mathrm{O}_{4} \mathrm{~F}$ requires $\mathrm{C}, 66.67 ; \mathrm{H}$, 3.97; N, 7.41\%); $\mathrm{R}_{\mathrm{f}} 0.62\left(1: 4 \mathrm{EA} /\right.$ hexane) IR: $v_{\max }\left(\right.$ thin film/ $\left./ \mathrm{cm}^{-1}\right) 1755,1732(\mathrm{C}=\mathrm{O}), 1588(\mathrm{C}=\mathrm{C}$ aromatic $)$, 1481(N=N), $1250(\mathrm{C}-\mathrm{N}), 1181(\mathrm{C}-\mathrm{O}), 762(\mathrm{C}-\mathrm{F}),{ }^{1} \mathrm{H}$ NMR (500 MHz, DMSO-d 6$)^{8} \mathrm{H}(\mathrm{ppm}): 8.20(\mathrm{~d}, \mathrm{~J}=8.6 \mathrm{~Hz}$, $\left.1 \mathrm{H}, \mathrm{Ar}-\mathrm{H}_{15}\right), 8.02\left(\mathrm{~d}, \mathrm{~J}=6.9 \mathrm{~Hz}, 2 \mathrm{H}, \mathrm{Ar}-\mathrm{H}_{8}\right), 7.79\left(1 \mathrm{H}, \mathrm{t}, \mathrm{J}=8.6 \mathrm{~Hz}, \mathrm{Ar}-\mathrm{H}_{1}\right), 7.74\left(\mathrm{t}, \mathrm{J}=8.6 \mathrm{~Hz}, 1 \mathrm{H}, \mathrm{Ar}-\mathrm{H}_{14}\right), 7.62(\mathrm{t}$, $\left.\mathrm{J}=6.9 \mathrm{~Hz}, 1 \mathrm{H}, \mathrm{Ar}-\mathrm{H}_{13}\right), 7.54-7.49\left(\mathrm{~m}, 4 \mathrm{H}, \mathrm{Ar}-\mathrm{H}_{5}, 6,9\right), 7.39-7.35\left(\mathrm{~m}, 2 \mathrm{H}, \mathrm{Ar}-\mathrm{H}_{2}, 12\right), 2.27\left(\mathrm{~s}, 3 \mathrm{H},-\mathrm{CH}_{3}\right),{ }^{13} \mathrm{C}$ NMR (125 MHz, DMSO-d $)_{6}{ }^{\delta} \mathrm{C}(\mathrm{ppm}): 169.3\left(\mathrm{C}_{\mathrm{b}}=\mathrm{O}\right), 162.4\left(\mathrm{C}_{\mathrm{a}}=\mathrm{O}\right), 160.4\left(\mathrm{Ar}-\mathrm{C}_{3}\right), 158.4\left(\mathrm{Ar} \mathrm{C}_{10}\right), 152.8\left(\mathrm{Ar}-\mathrm{C}_{11}\right)$, $150.6\left(\mathrm{Ar}^{-\mathrm{C}_{7}}\right), 150.0\left(\mathrm{Ar}_{\mathrm{C}} \mathrm{C}_{4}\right), 139.7\left(\mathrm{Ar}-\mathrm{C}_{13}\right), 135.4\left(\mathrm{Ar}-\mathrm{C}_{1}\right), 133.8\left(\mathrm{Ar}-\mathrm{C}_{15}\right), 131.9\left(\mathrm{Ar}-\mathrm{C}_{14}\right), 126.6\left(\mathrm{Ar}-\mathrm{C}_{6}\right), 125.1$ $\left(\mathrm{Ar}-\mathrm{C}_{5}\right), 124.3\left(\mathrm{Ar}-\mathrm{C}_{12}\right), 123.1\left(\mathrm{Ar}-\mathrm{C}_{8}\right), 121.9\left(\mathrm{Ar}-\mathrm{C}_{9}\right), 117.5\left(\mathrm{Ar}-\mathrm{C}_{16}\right), 117.3\left(\mathrm{Ar}-\mathrm{C}_{2}\right), 20.8\left(-\mathrm{CH}_{3}\right)$.

\section{2-[(E)-(Chlorophenyl)diazenyl]phenylaspirinate (2e)}

(0.54 g, 46\%) orange solid m.p. $119-120^{\circ} \mathrm{C}$. (Found: C, 63.66; H, 3.76; N, 6.98\% $\mathrm{C}_{21} \mathrm{H}_{15} \mathrm{~N}_{2} \mathrm{O}_{4} \mathrm{Cl}$ requires C, 63.88; $\mathrm{H}, 3.80 ; \mathrm{N}, 7.10 \%) ; \mathrm{R}_{\mathrm{f}} 0.62\left(1: 4 \mathrm{EA} /\right.$ hexane) IR: $v_{\max }\left(\right.$ thin film $\left./ \mathrm{cm}^{-1}\right) 1770,1742(\mathrm{C}=\mathrm{O}), 1591(\mathrm{C}=\mathrm{C}$ aromatic $)$, 1482(N=N), $1244(\mathrm{C}-\mathrm{N}), 1184(\mathrm{C}-\mathrm{O}), 753(\mathrm{C}-\mathrm{Cl}),{ }^{1} \mathrm{H}$ NMR (500 MHz, DMSO-d $\left.{ }_{6}\right){ }^{8} \mathrm{H}(\mathrm{ppm}): 8.21$ (d, J = 8.0 Hz, $\left.1 \mathrm{H}, \mathrm{Ar}-\mathrm{H}_{15}\right), 8.04\left(\mathrm{~d}, \mathrm{~J}=8.6 \mathrm{~Hz}, 2 \mathrm{H}, \mathrm{Ar}-\mathrm{H}_{8}\right) 7.80\left(\mathrm{t}, \mathrm{J}=7.8 \mathrm{~Hz}, 1 \mathrm{H}, \mathrm{Ar}-\mathrm{H}_{14}\right), 7.74\left(\mathrm{~d}, \mathrm{~J}=8.0 \mathrm{~Hz}, 1 \mathrm{H}, \mathrm{Ar}-\mathrm{H}_{5}\right), 7.70$ $\left(1 \mathrm{H}, \mathrm{d}, \mathrm{J}=8.0 \mathrm{~Hz}, \mathrm{Ar}-\mathrm{H}_{2}\right), 7.58\left(\mathrm{t}, \mathrm{J}=7.8 \mathrm{~Hz}, 1 \mathrm{H}, \mathrm{Ar}-\mathrm{H}_{13}\right), 7.55-7.48\left(\mathrm{~m}, 4 \mathrm{H}, \mathrm{Ar}-\mathrm{H}_{1,6,9}\right), 7.36(\mathrm{~d}, \mathrm{~J}=7.5 \mathrm{~Hz}, 1 \mathrm{H}$, $\left.\mathrm{Ar}-\mathrm{H}_{12}\right), 2.28\left(\mathrm{~s}, 3 \mathrm{H},-\mathrm{CH}_{3}\right),{ }^{13} \mathrm{C}$ NMR $\left(125 \mathrm{MHz}, \mathrm{DMSO}-\mathrm{d}_{6}\right){ }^{8} \mathrm{C}(\mathrm{ppm}): 169.4\left(\mathrm{C}_{\mathrm{b}}=\mathrm{O}\right), 162.1\left(\mathrm{C}_{\mathrm{a}}=\mathrm{O}\right), 152.6\left(\mathrm{Ar}-\mathrm{C}_{4}\right)$, $\left.150.2\left(\mathrm{Ar}^{-\mathrm{C}_{10}}\right), 149.5\left(\mathrm{Ar}-\mathrm{C}_{11}\right),\right), 147.4\left(\mathrm{Ar}-\mathrm{C}_{7}\right), 135.4\left(\mathrm{Ar}-\mathrm{C}_{13}\right), 133.9\left(\mathrm{Ar}-\mathrm{C}_{1}\right), 132.8\left(\mathrm{Ar}-\mathrm{C}_{15}\right), 131.9\left(\mathrm{Ar}-\mathrm{C}_{2}\right)$, $130.9\left(\mathrm{Ar}-\mathrm{C}_{3}\right), 128.2\left(\mathrm{Ar}-\mathrm{C}_{6}\right), 126.6\left(\mathrm{Ar}-\mathrm{C}_{14}\right), 124.5\left(\mathrm{Ar}-\mathrm{C}_{12}\right), 124.3\left(\mathrm{Ar}-\mathrm{C}_{5}\right), 123.2\left(\mathrm{Ar}-\mathrm{C}_{8}\right), 121.5\left(\mathrm{Ar}-\mathrm{C}_{9}\right), 117.6$ $\left(\mathrm{Ar}-\mathrm{C}_{16}\right), 20.8\left(-\mathrm{CH}_{3}\right)$.

\section{Antibacterial screening}

The inhibition activity of 1a-e and 2a-e against E. coli and $S$. aureus are shown in Figure 1 and Figure 2, respectively. Most halogenated azo derivatives $\mathbf{1 b}$-e showed good antibacterial activities against $E$. coli and $S$. aureus at all concentration (50,80 and $100 \mathrm{ppm})$. However, 2a-e only showed good inhibition activity against bacteria at high concentrations $(100 \mathrm{ppm})$. The effects of synthesized compounds tested at three different concentrations (50, 80 and $100 \mathrm{ppm})$ are further revealed by minimum inhibitory concentration (MIC) values. The MIC value of 1a-e and 2a-e were determined by extrapolating the concentration to zero growth rates of $E$. coli and S. aureus [16]. 
Zainab \& Boon: SYNTHESIS AND ANTIBACTERIAL ACTIVITY OF AZO AND ASPIRIN-AZO DERIVATIVES
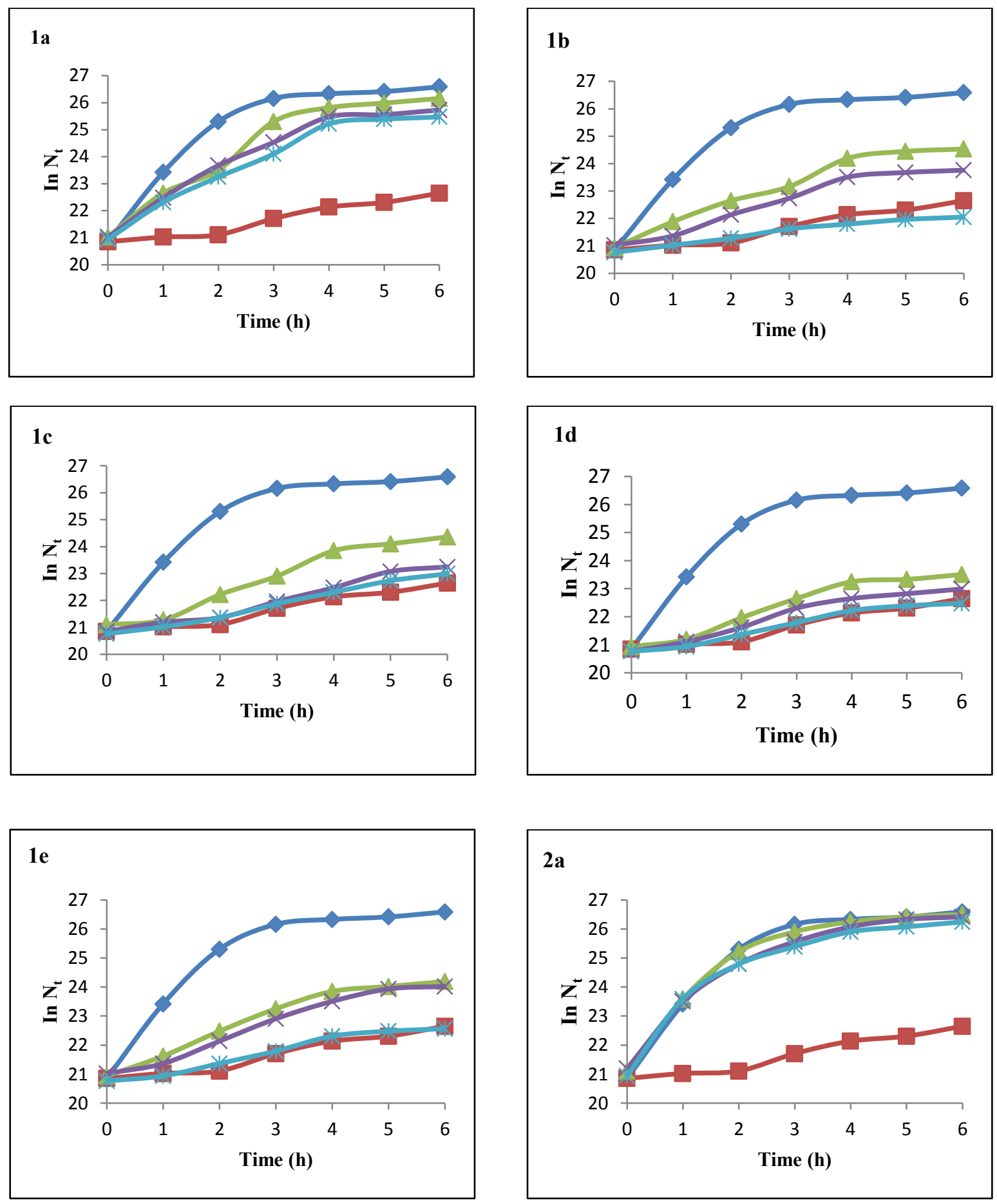

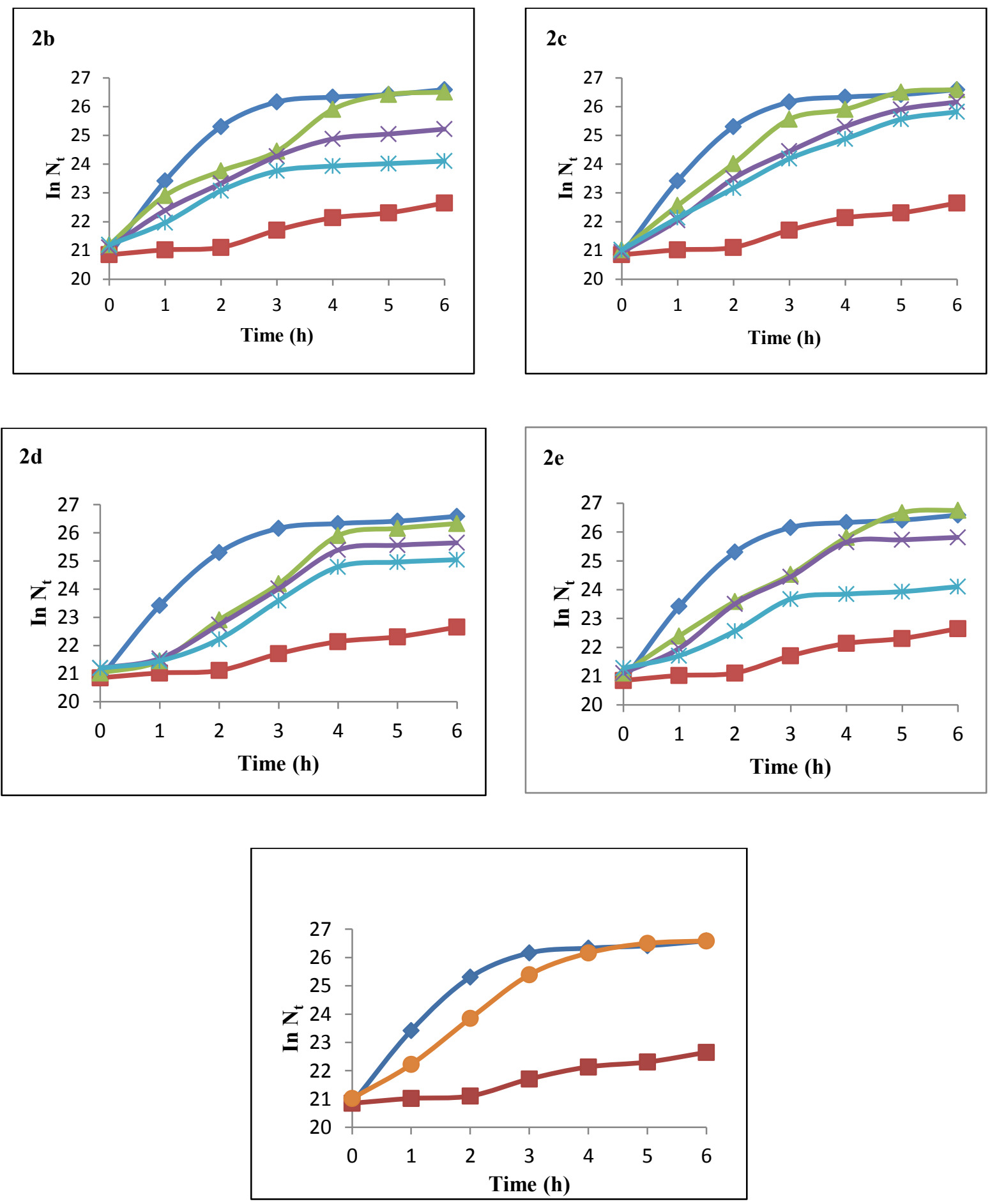

$\leadsto$ Control $(-) \multimap-\operatorname{control}(+) \multimap 50$ PPM $\leftarrow 80$ PPM $\leftarrow 100$ PPM $\multimap$ Aspirin

Figure 1. Inhibition activity of 1a-e and 2a-e against E. coli shown as $\operatorname{In} \mathrm{N}_{\mathrm{t}}$ for $E$. coli growth versus time. 
Zainab \& Boon: SYNTHESIS AND ANTIBACTERIAL ACTIVITY OF AZO AND ASPIRIN-AZO
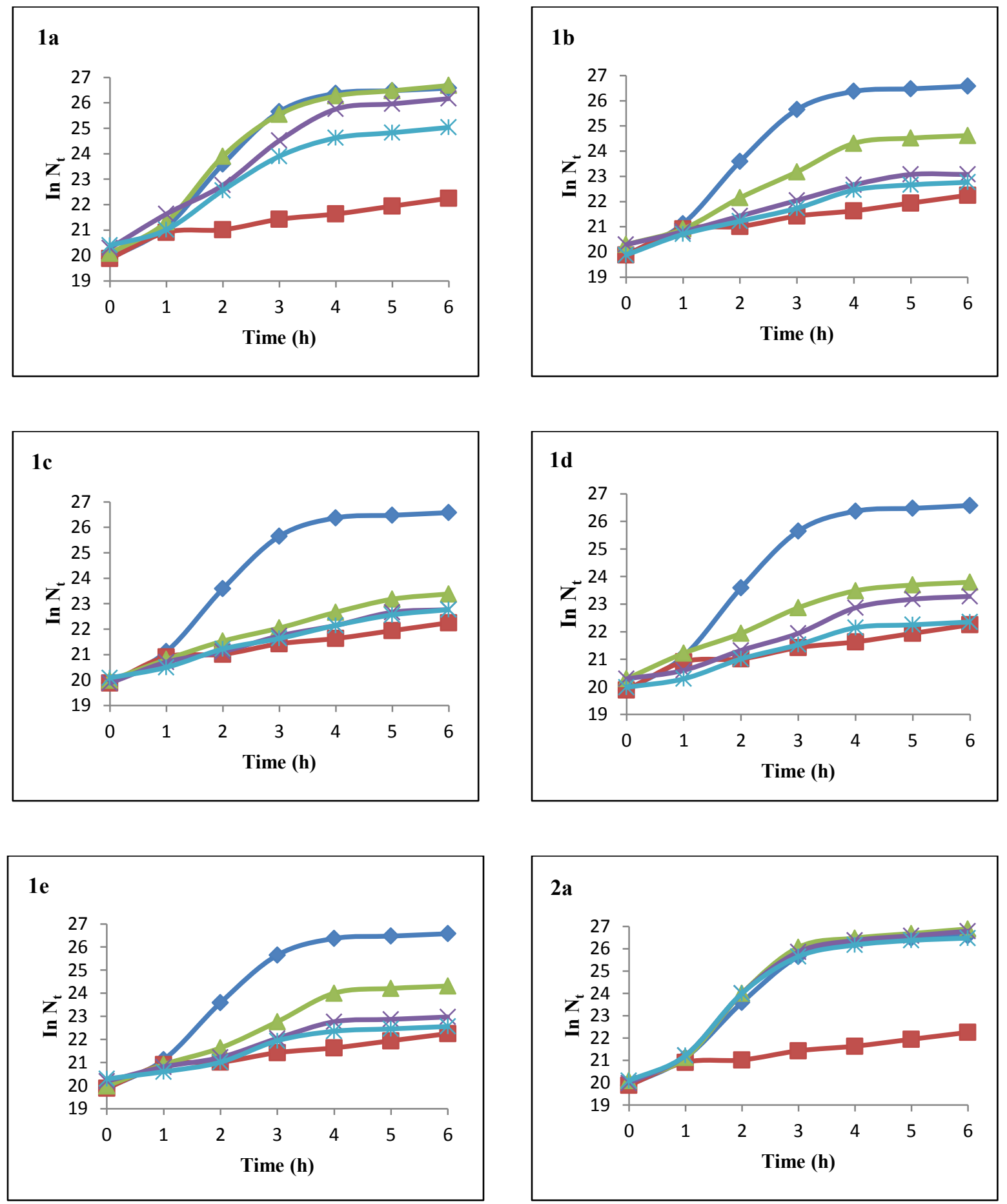

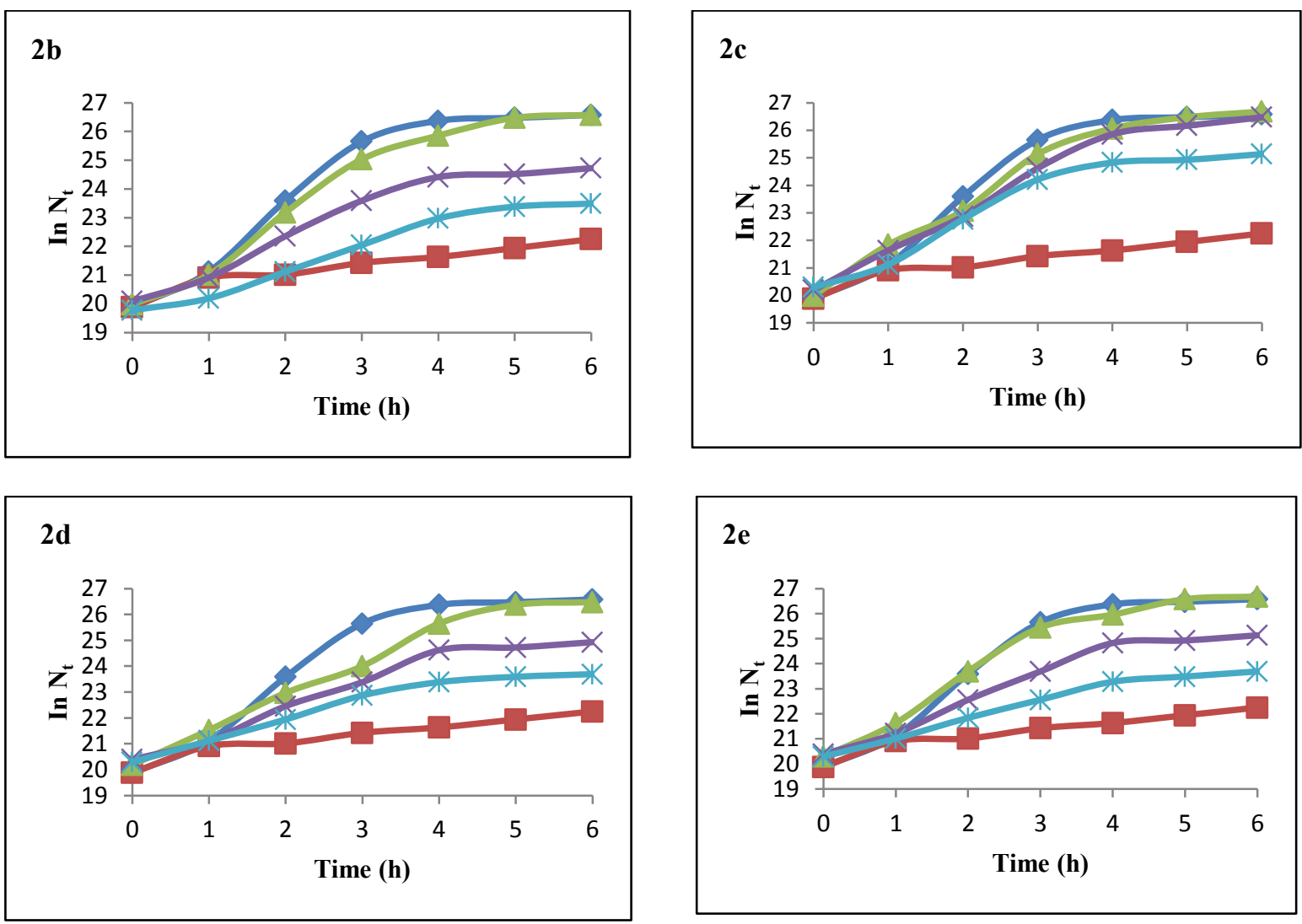

$\sim$ Control (-) $\neg-$ control $(+) \leftarrow 50$ PPM $\leftarrow 80$ PPM $\approx 100$ PPM $\multimap$ Aspirin

Figure 2. Inhibition activity of aspirin, 1a-e and 2a-e against S. aureus shown as $\mathrm{In}_{\mathrm{t}}$ for $S$. aureus growth versus time

Based on the MIC values shown in Table 1, the MIC values showed that all halogenated azo derivatives 1b-e exhibited very good bacteriostatic activities against $E$. coli and $S$. aureus compared to 1a (without halogen substituent). All the synthesized halogenated azo derivatives 1b-e demonstrated good inhibition against E. coli $(\mathrm{MIC}<220 \mathrm{ppm}$ ) and $S$. aureus (MIC $<220 \mathrm{ppm}$ ), which indicated that these compounds are a potential antibacterial agent [18]. Among these compounds, 1d (ortho fluorine atom substituent) gave the best inhibition with MIC values of $108 \mathrm{ppm}$ and $132 \mathrm{ppm}$ against $E$. coli and $S$. aureus, respectively. These results in agreement with Saeed et al. and Yarovenko et al. which reported that the halogen group and $\mathrm{N}=\mathrm{N}$ played important roles in antibacterial activities $[19,20]$. Furthermore, compounds consist of phenyl groups and halogen atoms have also revealed that those with more lipophilic character could easily penetrates the cell wall of microorganism [21, 22]. The azo derivatives $\mathbf{1 b}-\mathbf{e}$ consists of $-\mathrm{N}=\mathrm{N}$ - group can be protonated under acidic condition to react with the phosphate group on the polysaccharide peptidoglycan layer of bacteria, which hinder the formation of cell wall [23, 24]. Patrick also reported that the halogenated compound was involved in inhibition of bacteria via interaction of halogen with receptor of enzyme [25]. In addition, The $-\mathrm{N}=\mathrm{N}$ - and $\mathrm{OH}$ group in the synthesized halogenated azo derivatives $\mathbf{1 b}$-e interacts with active site on the enzyme of $E$. coli and $S$. aureus through hydrogen bond formation, thus inhibit the growth of bacteria [26].

For compound $\mathbf{2 a - e}$, only $\mathbf{2 b}$ and $\mathbf{2 d - e}$ exhibited good antibacterial activity against $E$. coli and $S$. aureus compared to 2a (without halogen substituent) and aspirin. It is because the presence of halogen substituent and $\mathrm{N}=\mathrm{N}$ in 
molecular structure has contributed to antibacterial activities. The $\mathbf{2 d}$ and $\mathbf{2 e}$ substituted with fluorine and chlorine atoms, respectively at ortho position are more active to inhibit towards E. coli and S. aureus compared to compounds substituted with halogen atom at meta position. These results also revealed the same finding in which the halogen substituted at different position may have effect on the antibacterial activity as reported Lee et al. [27]. Furthermore, presence of more phenyl ring in molecular structure might also result in bulkiness. Therefore, it is more difficult to penetrate into bilayer of phospholipid E. coli and S. aureus [28].

Table 1. Minimum inhibitory concentration (MIC ppm) for compound 1a-e and 2a-e

\begin{tabular}{lcc}
\hline \multirow{2}{*}{ Compounds } & \multicolumn{2}{c}{ MIC (ppm) } \\
\cline { 2 - 3 } & E. coli & S. aureus \\
\hline Aspirin & $>220$ & $>220$ \\
$\mathbf{1 a}$ & $>220$ & $>220$ \\
$\mathbf{1 b}$ & 113.4 & 150.2 \\
$\mathbf{1 c}$ & 111.3 & 139.0 \\
$\mathbf{1 d}$ & 108.5 & 132.3 \\
$\mathbf{1 e}$ & 117.3 & 138.3 \\
$\mathbf{2 a}$ & $>220$ & $>220$ \\
$\mathbf{2 b}$ & 180.9 & 194.1 \\
$\mathbf{2 c}$ & $>220$ & $>220$ \\
$\mathbf{2 d}$ & 156.3 & 199.5 \\
$\mathbf{2 e}$ & 167.0 & 198.9 \\
Ampicillin $(+)$ & 92.9 & 124.2 \\
\hline
\end{tabular}

\section{Conclusion}

In conclusion, there are two series of azo derivatives $\mathbf{1 b}$-e and aspirin-azo derivatives $\mathbf{2} \mathbf{b}-\mathbf{e}$ were synthesized and screened for their antibacterial activities. The results showed that all halogenated azo derivatives $\mathbf{1 b}$-e exhibited better antibacterial activities against both gram-negative bacteria and gram-positive bacteria when compared to all aspirin- azo derivatives $\mathbf{2 b}$-e. The esterification of aspirin with azo derivatives $\mathbf{1 b}$-e had increased the bulkiness of the molecular structure causing the steric hindrance, thus avoid the molecular structure from binding to the active site of bacteria. In addition, the bulky structure has caused difficulty to penetrate into the cell wall of bacteria. Azo derivatives 1d bearing fluorine atom gave excellent antibacterial properties and gave the lowest MIC value due to the smaller size of fluorine.

\section{Acknowledgements}

The authors would like to thank university Malaysia Sarawak and Ministry of Higher Education for financial support of this project through grant FRGS/(ST01(02)/968/2013(09).

\section{References}

1. Richard, C. B. (2012). Aspirin and the prevention of venous thromboembolism. New England Journal of Medicine, 366: 2028 - 2030.

2. Cemel, A. and Ahmet, S. (2008). Rapid and simultaneous determination of acetylsalicylic acid, paracetamol and their degradation and toxic impurity product by HPLC in pharmaceutical dosage forms. Journals Medical Science, 38: $167-173$.

3. Warner, T. D., Nylander, S. and Whatling, C. (2011). Anti-platelet therapy: cyclo-oxygenase inhibition and the use of aspirin with particular regard to dual anti-platelet therapy. British Journal of Clinical Pharmacology, $1365-2125$.

4. Vane, J. R. and Botting, R. M. (2003). The mechanism of action of aspirin. Thrombosis Research, 110: 255 258. 
5. Cicala, C., Ianaro, A., Fiorucci, S., Calignano, A., Bucci, M. and Gerli, R. (2000). NO-naproxen modulates inflammation, nociception and downregulates T cell response in rat Freund's adjuvant arthritis. British Journal of Pharmacology, 130: $1399-1405$.

6. Al-Bakri, A. G., Othman, G. and Bustanji, Y. J. (2009). The assessment of the antibacterial and antifungal activities of aspirin, EDTA and aspirin-EDTA combination and their effectiveness as antibioflim agents. Applied Microbiology, 107(1): 280 - 296.

7. Huang, L., MacKenzie, G. G., Ouyang, N., Sun, Y., Xie, G., Johnson, F., Komninou, D. and Rigas, B. (2011). The novel phospho-non-steroidal anti-inflammatory drugs, OXT-328, MDC-22 and MDC-917, inhibit adjuvant-induced arthritis in rats. British Journal of Pharmacology, 162(7): 1521 - 1533.

8. Joseph, S., Nie, T., Huang, L., Zhou, H., Atmakur, K., Gupta, R. C., Johson, F. and Rigas, B. (2011). Structureactivity relationship study of novel anticancer aspirin-based compounds. Molecular Medicine Reports, 4(5): $891-899$.

9. Hinks, D., Freeman, H. S., Nakpathom, M. and Sokolowska, J. (2000). Synthesis and evaluation of organic pigments and intermediates. 1. Nonmutagenic benzidine analogs. Dyes and Pigments, 44: 199-207.

10. Simu, G. M. and Kurunczi, L. (2008). Influence of temperature and of the electrolyte concentration in the dyeing process of a cellulosic fibre with a disazo direct dye. Chemical Bulletin, 53(67): $153-155$.

11. Ahmed, A. E. I., Hay, J. N., Bushell, M. E., Wardell, J. N. and Cavalli, G. (2008). Biocidal polymer (I): Preparation and biological activity of some novel biocidal polymers based on uramil and its azo-dyes. Reactive and Functional Polymers, 68(1): 248 - 266.

12. Khalid, A, Arshad. M. and Crowley, D. E. (2008). Accelerated decolorization of structurally different azo dyes by newly isolated bacterial strains. Applied Microbiology, 78: $361-369$.

13. Raghavendra, K. R. and Kumar, K. A. (2013). Synthesis of some novel azo dyes and their dyeing, redox and antifungal properties. International Journal of ChemTech Research, 5(2): 1756 - 1760.

14. Tonelli, I. M., Vazzana, B., Jasso, V., Boida, F., Sparatore, P., Lacolla, G., Sanna, G., Giliberti, B., Busonera, P., Farci, C. I. and Loddo, R. (2009). Antiviral and cytotoxic activities of aminoarylazo compounds and aryltriazene derivatives. Bioorganic and Medicinal Chemistry, 17: 4425 - 4440.

15. Ho, B. K., Ngaini, Z. Neilsen, P. M., Hwang, S. S., Linton, R. E., Kong, E. L., and Lee, B. K. (2017). Synthesis and Anticancer Activities of 4-[(Halophenyl)diazenyl]phenol and 4-[(Halophenyl)diazenyl]phenyl Aspirinate Derivatives against Nasopharyngeal Cancer Cell Lines. Journal of Chemistry, 2017: 1-7.

16. Pappano, N. B., Puig de Centorbi, O., Debattista, N. B., Calleri de Milan, C., Borkowski, E. J. and Ferretti, F. H. (1985). Kinetic of the bacteriostatic activity of natural and synthetic chalcones on a strain Staplylococcus aureus. Revista Argentina De Microbiologia, 17: 27 - 32.

17. Solomons. T. W. G. and Fryhle, C. B. (2003). Organic Chemistry ( $8^{\text {th }}$ edition). John Wiley \& Sons: USA.

18. Arslan, H., Duran, N., Borekei, G., Oxer, C. K. and Akbay, C. (2009). Antimicrobial activity of some thiourea derivatives and their nickel \& copper complexes. Molecules, 10(14): 519 - 527.

19. Saeed, A., Abbas, N., Rafique, H., Rashid, S. and Hammed, A. (2009). Synthesis characterization and antibacterial activity of some 1-aroyl-3-aryl thiourea. Chemistry, 18(5): $152-158$.

20. Yarovenko, V. N., Lysenko, O. V. and Krayushkin, M. M. (1993). Synthesis of derivatives 2-amino-1,3,4oxadiazole-5- hydroxamic acid. Chemistry of Heterocyclic Compounds, 29(4), 452 - 454.

21. Ansari, M. M., Deshmukh, S.P., Khan, R. and Musaddiq, M. (2014). Synthesis antimicrobial and anticancer evaluation of 1-aryl-5-(o-methoxyphenyl)-2-S-benzyl isothiobiurets. International Journal of Medicinal Chemistry, 2014: $1-5$.

22. Hoey, A. J., Jackson, C. M., Pegg, G. G. and Sillence, M. N. (1996). Characteristics of cyanopindolol analogues active at the beta (3)-adrenoceptor in rat ileum. British Journal of Pharmacology, 119: 564 - 568.

23. Brown, S., Santa, M. J. P. and Walker, S. (2013). Wall teichoic acids of gram-positive bacteria. Annual Review of Microbiology, 67(1): 313 - 336.

24. Zhong, Z., Xing, R., Liu, S., Wang, L., Cai, S. B. and Li, P. C. (2008). Synthesis of acyl thiourea derivatives of chitosan and their antimicrobial activities in vitro. Carbohydrate research, 334(3): $566-570$.

25. Patrick, G. L. (2009) Medicinal chemistry ( $4^{\text {th }}$ edition). Oxford University Press Inc: Asia.

26. Khalaf, Y. H. (2008). Synthesis a number of azo compounds derived from guanine and studying their biological activity on pathogenic bacteria. Journal of Al-Anbar University for Pure Science, 2(3): 38 - 45.

27. Li, J., Rao, X. P., Shang, S. B., Gao, Y. Q. and Song, J. (2012). Synthesis and antibacterial activity of amide derivatives from acrylopimaric acid. Bioresources, 7(2): $1961-1971$. 
Zainab \& Boon: SYNTHESIS AND ANTIBACTERIAL ACTIVITY OF AZO AND ASPIRIN-AZO DERIVATIVES

28. Fernandez, E. R., Manzano, J. L., Benito, J. J., Hermosa, R., Monte, E. and Criado, J. J. (2005). Thiourea, triazole and thiadiazine compounds and their metal complexes as antifungal agents. Journal of Inorganic Biochemistry, 99: 1559 - 1572. 